\title{
The Sarcheshmeh thickened tailings disposal project
}

\author{
L. MacNamara FLSmidth Ltd, United Kingdom
}

N. Khoshniaz National Iranian Copper Industries Company, Islamic Republic of Iran

S. Hashemi CanyMes Engineering and Technical Services, Islamic Republic of Iran

\begin{abstract}
The National Iranian Copper Industries Company owns and operates three concentrators in the Islamic Republic of Iran. The largest of these three operations is the Sarcheshmeh complex, which has been in operation since the early 1980s and now treats over 65,000 tpd of copper ore. An expansion to 96,000 tpd is planned to come on stream in the next few years.

Water is a limited resource in this very arid area the water management of the whole operation was reviewed when the expansion was proposed. A thickened tailings disposal scheme was proposed using twelve $24 \mathrm{~m}$ Eimco deep cone thickeners. This scheme would increase water recovery and allowed the existing tailings facility to be expanded with minimal cost to provide capacity for the next 30 years production.
\end{abstract}

This paper outlines the design challenges associated with an installation of multiple thickeners and the unique solutions that have been used to provide a flexible plant design.

\section{Introduction}

The National Iranian Copper Industries Company (NICICO) was established in 1976. Until 2001 their main operation was the then 14 Mtpa copper complex located at Sarcheshmeh in Kerman Province, southeastern Iran. The complex consisted of the 1.2 billion tonne Sarcheshmeh ore body and processing and smelting facilities to produce 200,000 tpa copper cathode and wire bar. Through a series of expansions and new projects planned in the late 1990s and put into operation between 2002 and 2004 total copper production in Iran was increased to 240,000 t of refined copper per year. An integral part of these expansions, in the face of decreasing head grades, was to increase throughput at the Sarcheshmeh concentrator initially to 67,000 tpd and then to 96,000 tpd with two plant expansions. Two new copper mines were built - a 7 Mtpa operation at Sungun and a 5 Mtpa operation at Miduk.

At Miduk, the topography in the vicinity of the mine was such that a down valley discharge system had to be used for the design of the tailings facility and in order to achieve the required beach slope in the tailings dam, four Eimco deep cone thickeners were used to dewater the plant tailings. These paste thickeners produce high solids concentration underflow whose viscous properties can be used to implement new tailings disposal methods such as thickened tailings disposal and also increases water recovery. This was the first implementation of paste thickeners on copper tailings worldwide. The Miduk operation is described in detail elsewhere (Williams et al., 2006).

When the expansion of the Sarcheshmeh operation was proposed, the capacity of the existing tailings facility had to be considered. The successful implementation of the thickened tailings disposal scheme at Miduk gave NICICO the confidence to implement this technology for the Sarcheshmeh expansion. The placement of thickened tailings from paste thickeners would allow the existing tailings facility to continue to be used, with a small expansion of the retaining walls, for the next 30 years. A significant saving in capital cost over a full dam raise or the development of a new facility.

Southeastern Iran has a very arid climate and water is scarce. The area also supports a large agricultural industry vital to the local and national economy. Water use in the region is, therefore, carefully managed and the proposed expansion at Sarcheshmeh had to also consider water preservation and recycling as a priority. 


\section{The Sarcheshmeh integrated water master plan}

The planned step change in production required a review of the existing tailings disposal strategy with regard to the projected tonnages of tailings and the capacity of the current tailings dam. If the tailings disposal method remained the same a new tailings facility would have to be built along with a series of new wells to provide extra water for the next thirty years of production. A number of sites were studied for a new tailings facility but all had problems and a raise of the existing facility was considered to be the best route to follow.

In order to maximise the capacity of the facility and minimise the work involved in raising the dam walls, and maximise the water recovery, a thickened tailings disposal scheme - using the same down valley discharge system implemented at Miduk was proposed as part of a wider water management plan.

Such was the limited volume of additional water that was available in the area that an increase in water recovery and re-use had to come into effect if there was ever going to be sufficient water available to treat the increased tonnage of ore planned for the complex. The added benefit of a thickened tailings disposal scheme was the additional water recovery and the positive impact this would have on the local water resources.

\section{The Sarcheshmeh tailings disposal project}

The tailings disposal project for Sarcheshmeh was conceived to treat the tailings from the original plant, the Phase I expansion and the proposed Phase II expansion. The total tonnage to the plant, once Phase II was brought on line would be $96,000 \mathrm{t}$ per day.

The tailings at the concentrator are dewatered in $122 \mathrm{~m}$ diameter Eimco tailings thickeners but these can only be operated to an underflow density of $40-45 \% \mathrm{w} / \mathrm{w}$ as the underflow passes to the tailings dam in a concrete lined channel winding almost $26 \mathrm{~km}$ from the plant down to the tailings dam. Originally designed in 1976 the tailings channel was not capable of transporting higher solids concentration slurry or paste.

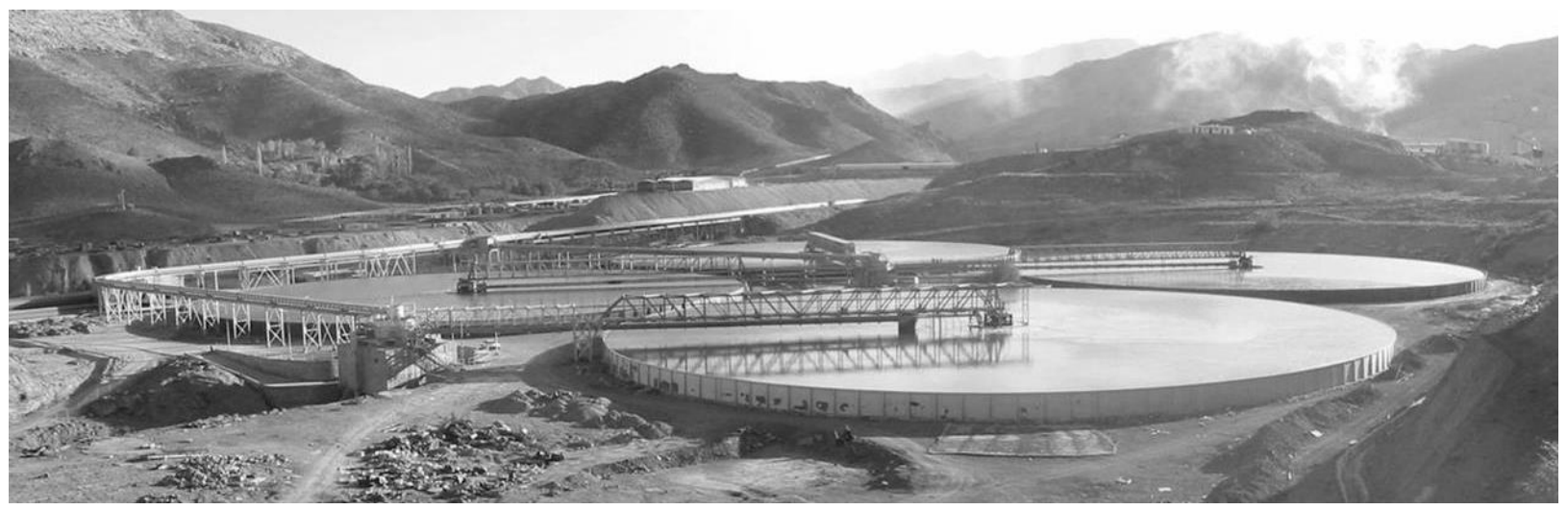

Figure 1 Four 122 m diameter Eimco tailings thickeners at the Sarcheshmeh complex

It was therefore decided to locate the new paste thickeners away from the main concentrator close to the tailings dam. The site chosen would allow the thickener underflow to be discharged into the tailings dam without the need for positive displacement pumps.

\section{Test work}

Test work to size the thickeners and determine the performance level was carried out in two phases:

- laboratory testing in the UK

- pilot testing onsite.

Laboratory testing was used to determine the optimum feed solids concentration, flocculant type and underflow rheology. 
Pilot testing was carried out to confirm the findings from the laboratory test work and confirm the thickener performance with a wider range of feed conditions than is possible from a single sample collected for lab testing. A series of six pilot plant runs were carried out each lasting between 45 and 100 hours.

The pilot test work confirmed the flocculant type and dose, the feed solids concentration required for optimum settling and the residence time required to achieve the maximum thickener underflow solids concentration.

The following design parameters were used to size the thickeners required for the main plant:

- Plant throughput: $\quad 96,000$ tpd.

- Unit area: $\quad 0.057 \mathrm{~m}^{2} / \mathrm{t} / \mathrm{d}$.

- Optimum feed solids: $15 \% \mathrm{w} / \mathrm{w}$.

- Flocculant dose: $25 \mathrm{~g} / \mathrm{t}$.

- Underflow density: $60 \% \mathrm{w} / \mathrm{w}$.

Based on these results from the test work, two options were considered for the required duty:

- 24 m diameter units: 12 deep cone thickeners.

- $34 \mathrm{~m}$ diameter units: 6 deep cone thickeners.

As the $34 \mathrm{~m}$ units were a design that had not been proven at the time, the decision was made to proceed with the proven $24 \mathrm{~m}$ Eimco deep cone thickener.

\section{$5 \quad$ Benefits of thickened tailings disposal}

The major benefits from the use of thickened tailings disposal for the Sarcheshmeh complex were:

- Increased water recovery by minimising losses through evaporation and seepage on the tailings dam. Increasing the solids content of the tailings placed in the tailings dam from $40-60 \% \mathrm{w} / \mathrm{w}$ would generate over 27 million $\mathrm{m}^{3}$ of process water a year - an increase in water recovery of 18 million $\mathrm{m}^{3}$ per year over the current practice.

- The viscous thickener underflow allows tailings storage with a beach slope, giving an additional 30 years capacity to the existing tailings dam with minimal work to raise the embankment.

- A thickened tailings disposal scheme would allow the Phase II expansion of the Sarcheshmeh operation to go ahead without the need for additional water extraction from the already limited available resources.

\section{$6 \quad$ Plant design considerations}

There were two major hurdles that had to be overcome in the plant design if the maximum performance was going to be achieved consistently:

- even distribution of the feed between the twelve operating thickeners

- controlled flocculation of the feed to each individual thickener.

For the plant to be able to achieve the design underflow density routinely these two factors had to be addressed.

\section{$7 \quad$ Feed distribution}

The feed distribution system has to be able to provide an even split between the individual thickeners in the plant under a wide range of operating conditions. Given the large volume of slurry being fed to the plant a gravity system was preferred to a pumped distribution system. The basis of the distribution system is a bottom fed circular distribution tank mounted on a tower. The tower is located to one side of the plant as shown in Figures 1 and 2. 
A bottom central entrance to the tank would allow twelve outlets arranged radially in the tank base to take feed to each of the thickeners individually. In order to ensure the same flow into each outlet, the system had to be designed with the same pressure loss in each pipe. Each thickener feed pipe had to be the same length and each one had to run full under a wide range of feed conditions to ensure the same pressure loss in the pipe. This could only be achieved in a conventional plant if the thickeners were arranged in a circle around the distribution tower. The available space for the installation of twelve units was however a strip of land atop a ridge so the installation would comprise two parallel rows of six thickeners each. A novel solution to distributing the feed had to be sought.

The simplest method to ensure that the twelve pipes feeding the thickeners all have the same pressure drop would be to ensure that each pipe was the same length. As this could not be achieved with the configuration of thickeners that was possible in the plant footprint, a solution where the thickener feed system was part pipe and part launder was used.

Each outlet from the distribution tower has exactly the same length of pipe, at the end of which is an orifice plate that ensures that the pipes will remain at full flow. The orifice plates are selected to maintain an operating depth of $1 \mathrm{~m}$ of slurry in the distribution tower at normal design conditions. After the orifice plate the feed system transitions into an open launder which runs to the thickener where the system converts back to a piped arrangement for feeding into the Eimco E-Duc system.

In this way, each thickener feed system can be guaranteed to have the same pressure loss and therefore each will have the same feed flow rate from the distribution tank.

The system also had to be designed to take into account fluctuations in the feed to the paste plant. The concentrators at Sarcheshmeh consist of the original plant treating 40-50,000 tpd and two expansions, each treating 25-27,000 tpd. The design of the original plant with multiple parallel lines of small equipment is such that the entire plant is rarely off line but the two expansions with SABC grinding circuits are taken off line completely periodically for SAG Mill relining. The plant feed distribution design parameters had to allow for variations in federate while maintaining even distribution to the thickeners.

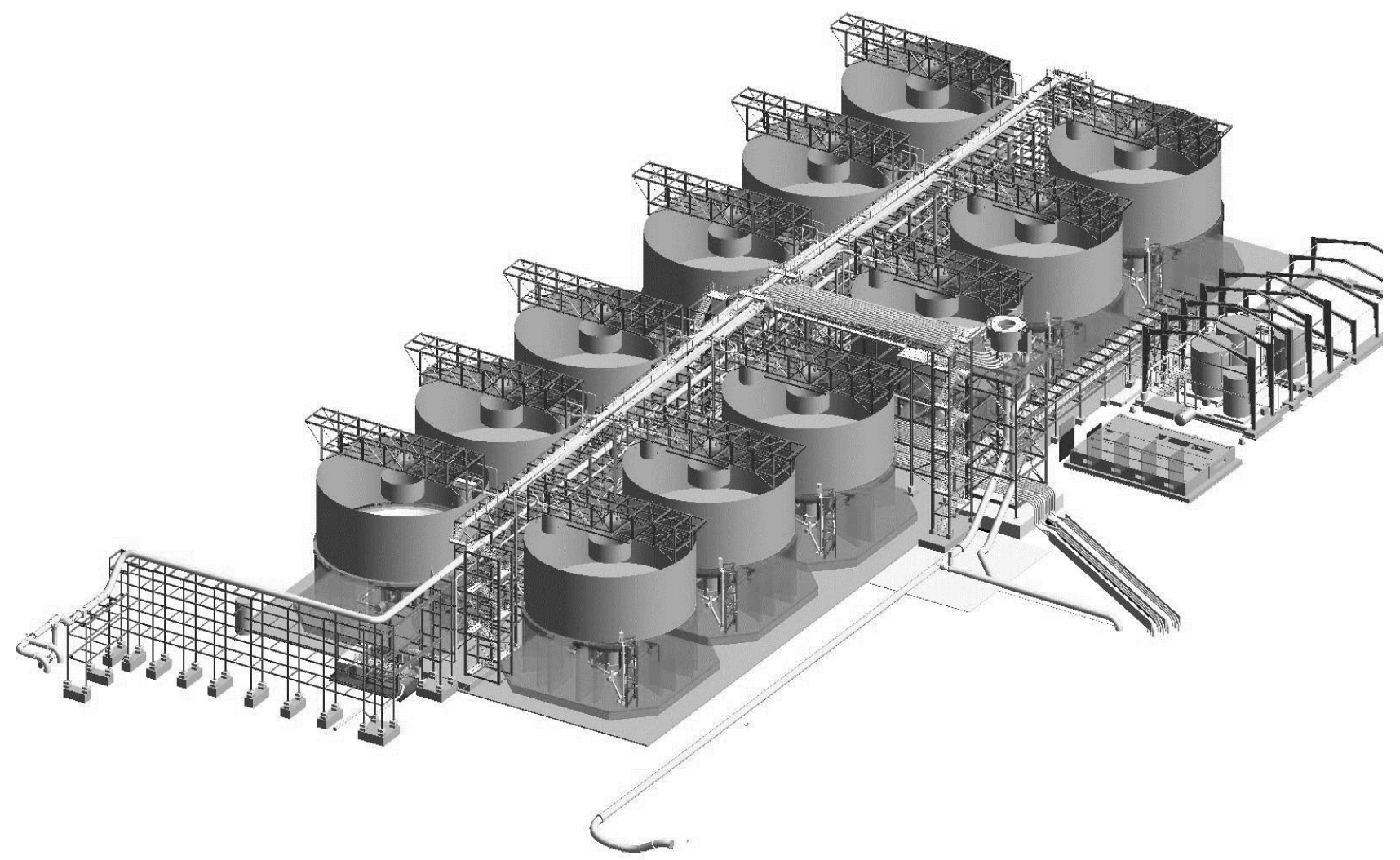

Figure 2 Layout of the Sarcheshmeh $12 \times 24 \mathrm{~m}$ deep cone thickener tailings treatment plant 


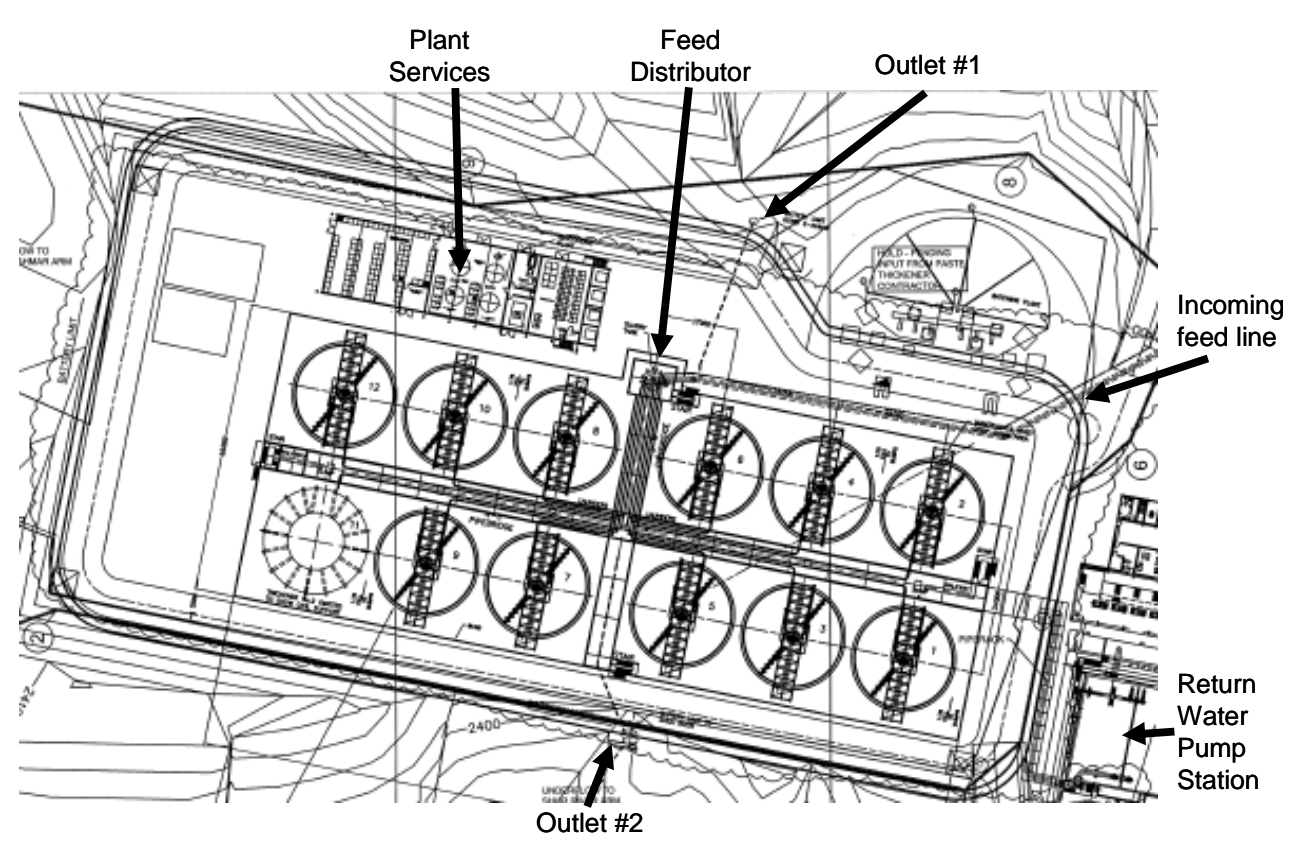

Figure 3 Plan of the Sarcheshmeh tailings treatment plant

The distribution tank was designed with a normal operating level of one metre of slurry and a maximum operating depth of three metres. The additional two metres will allow for an increase in feed rate to the thickeners of $25 \%$ before the distribution tank overflows. The tank overflow is piped to one of the plant outlet points. The outlets from the base of the tank are all fitted with actuated valves allowing thickeners to be brought online, or taken offline to maintain the operating depth in the tank between 1-3 $\mathrm{m}$.

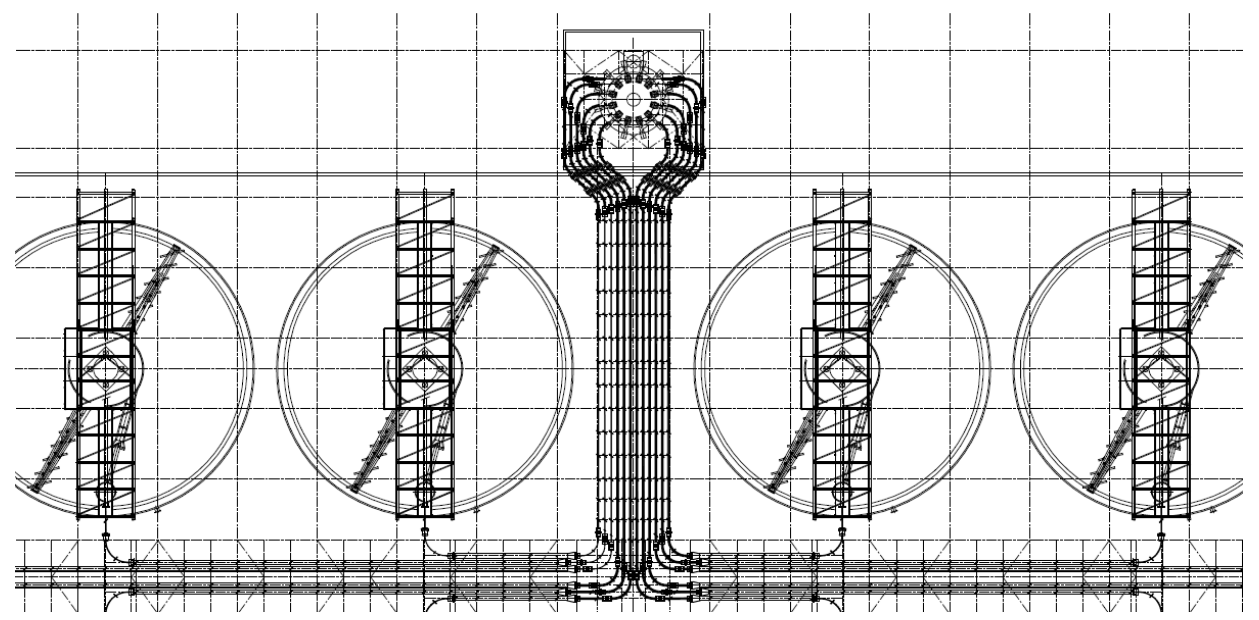

\section{Figure 4 Plant feed distribution system}

\section{$8 \quad$ Flocculant control}

The accurate control of the addition of flocculant to any thickener is important to achieve the best and most economic dewatering performance. This is especially true in a paste thickener where the thickening operating envelope is being pushed to its limit.

The addition of flocculant to a thickener can be controlled in a number of direct and indirect ways. Direct control of the flocculant addition would be through a variable speed dosing pump controlled to deliver a predetermined dose based on the incoming tonnage of solids to the thickener. The incoming feed solids flow rate is calculated after measurement of the feed flow rate and feed slurry relative density. An alternate direct control method is to measure the settling rate of the flocculated particles in the feedwell and control the 
flocculant dose rate to achieve a predetermined settling rate. Indirect methods of controlling the flocculant addition rate are through measurement of the solid/liquid interface and/or measurement of the inventory within the thickener through the static head inside the thickener. All measurements, to a greater or lesser extent are subject to changes in the feed characteristics and the response of the feed to flocculation.

The indirect measurement techniques were discarded for flocculant control though the static pressure within the tank and the bed level are measured for other purposes than flocculant control.

While there are a number of online methods for the measurement of settling rate within a thickener, which can be used to control the flocculant addition, it was felt that these were yet to be proven on a copper tailings application so alternate methods were considered.

The simplest and most reliable method of controlling flocculant dose rate to a thickener is to measure the feed flow rate and feed slurry specific gravity and calculate the actual tonnage of solids being fed to the thickener. There were several obstacles to be overcome if this approach was to be used for the Sarcheshmeh paste thickener plant.

The first major obstacle to overcome in the instrumentation and control of the Sarcheshmeh paste thickener plant is the sheer scale of the operation. The feed pipe is $1,024 \mathrm{~mm}$ - too large for a magnetic flow meter or standard nucleonic density gauge. A common feed flow measurement on the pipe into the distribution box would also not take into account any variations that might exist in the distribution of feed between the operating thickeners - no matter how well designed the feed distribution system was.

This problem was overcome in two ways. Firstly, a bleed line was taken from the distribution tank, which fed into a standard centrifugal pump on the plant floor below the tower. This pump then circulated a small stream of feed back to the distribution tower through a simple standard density gauge. Secondly, a system to measure the feed flow rate to each thickener was designed.

The flow rate to each thickener should be equal. However, to ensure the best and most accurate flocculant control, the flow rate to each thickener would be measured. While the outlet distributors and orifice plates should ensure flooded pipe conditions in the outlets from the distribution tower, magnetic flow meters could not be installed in an 'upflow' situation so these were disregarded. Instead a 'depth of flow' measurement system was included.

Each thickener feed pipe had a transition from pipe flow, through an orifice to open channel flow. Above each open channel an ultrasonic depth indicator was located which, knowing the launder profile and angle, the output can be used to calculate the flow.

The feed flow rate in the channel can be calculated from the flow cross sectional area and the flow velocity. The feed velocity can be calculated from depth of flow in a channel of known dimensions using the Gauckler-Manning-Strickler formula:

$$
V=\frac{1}{n} R_{h}^{\frac{2}{3}} \cdot S^{\frac{1}{2}}
$$

Where:

$\mathrm{V}=\quad$ is the cross-sectional average velocity.

$\mathrm{n}=\quad$ is the Gauckler-Manning coefficient.

$\mathrm{R}_{\mathrm{h}}=$ is the hydraulic radius.

$\mathrm{S}=\quad$ is the slope of the water surface.

For a channel of known dimensions the distance from a known fixed point to the surface of the liquid can therefore be used to calculate the flow velocity and therefore the flow rate.

In this way the flow and feed slurry relative density are known and the speed of the flocculant dose pump can be controlled to deliver a predetermined dose rate. 


\section{Construction}

The remote location of the mine site, and the thickener plant in particular presented several logistical and planning challenges. These were mainly due to the topography of the location of the site chosen by the tailings dam designers as the optimum location for the thickeners and the discharge into the tailings dam which resulted in little available lay down area for the construction phase.

Further challenges were felt in the materials available for the construction of the thickener tanks, in particular the steel required for the tank bases.

The sheer size and nature of the inventory of paste thickeners develop significant loads in the base of the cone. As a result, thickeners of this type and size required for the Sarcheshmeh project can require plate up to $25 \mathrm{~mm}$ thick in areas. The skills required to weld very thick plates over multiple runs to a high degree of repeatability was taken into consideration in the selection of the design of the thickener tanks, as well as the availability of steel of a suitable strength.

Iran is a highly seismic country and the design loads on the tank supports have to be able to cope with very high sideways loads generated under earthquake conditions. This would also require particular steel sections for the structural supports, not widely available in Iran.

Taking all these things into consideration, the final tank design was one based on a concrete cone, supported on concrete ribs and then topped with a steel side wall tank. While this presented a number of challenges in the construction of the formwork, it was felt that this method offered the best opportunity, with the materials easily available locally, for a successful and timely implementation of the construction phase of the project.

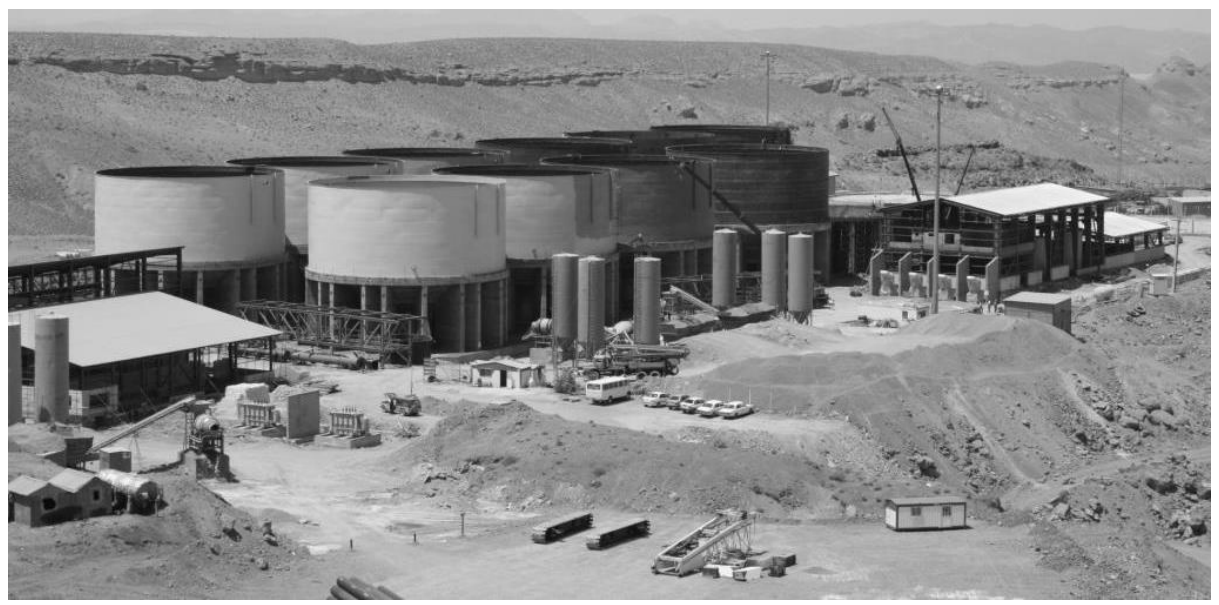

\section{Figure 5 The plant under construction}

\section{Conclusions}

A new tailings disposal facility has been designed and is nearing completion at NICICO's Sarcheshmeh Mine, Kerman Province, Iran. The new facility consists of a remote stand alone plant located at the tailings dam and consists of twelve $24 \mathrm{~m}$ diameter Eimco deep cone thickeners.

The plant will allow tailings with a relative density of up to $1.6 \mathrm{t} / \mathrm{m}^{3}$ to be placed directly into the tailings dam without the need for positive displacement pumps. The thickener overflow will recycle up to 28 million $\mathrm{m}^{3}$ of process water back to the plant per year at full production. The plant will be commissioned in phases with Phase I coming online in late 2011.

\section{References}

Williams, M.P.A., Murphy, S.D., MacNamara, L. and Khoshniaz, N. (2006) The Miduk Copper Project: Down Valley Discharge of Paste Thickened Tailings, Design and Early Operating Experience, in Proceedings Ninth International Seminar on Paste and Thickened Tailings (Paste06), R.J. Jewell, S. Lawson and P. Newman (eds), 3-7 April 2006, Limerick, Ireland, Australian Centre for Geomechanics, Perth, pp. 117-130. 
